\title{
MECONIUM AND URINARY PATTERNS OF HEALTHY TERM NEWBORNS IN A TERTIARY CARE HOSPITAL OF WESTERN NEPAL- A PROSPECTIVE OBSERVATIONAL STUDY
}

Badri Kumar Gupta ${ }^{1}$, Raju Kaphle ${ }^{1}$, Binod Kumar Gupta ${ }^{1}$, Sandeep Shrestha ${ }^{2}$, Navneet Raj Kumar ${ }^{3}$, Nagendra Chaudhary ${ }^{1}$

\begin{abstract}
\section{INTRODUCTION}

The time of passage of the newborn's first meconium/stool is an indicator of health and is used to screen for normal gastrointestinal tract function. Most newborns urinate after birth, and this is an indication of normal renal function. The aim of this study is to investigate the meconium/stool and urinary patterns of healthy neonates so that it will help us to know the average time of passing meconium and Urine in newborns.
\end{abstract}

\section{MATERIAL AND METHODS}

A hospital based observational study was conducted for a period of one year in healthy term newborns delivered at UCMS$\mathrm{TH}$, a tertiary care hospital in western Nepal. Newborns with a gestational age of $\geq 37$ weeks delivered by normal vaginal delivery or cesarean section were included. The newborns were fed either breast milk exclusively or a combination of breast milk and formula. The frequency of meconium/stool and urine passage were recorded throughout their hospital stay with their timings. Babies with congenital anomalies were excluded from the study (like imperforate anus, cleft lip and palate and spina bifida, colloidal baby).

\section{RESULTS}

Out of 1050 delivered babies, 5 were excluded from final analysis as they did not meet the inclusion criteria. The study showed that majority $(97.8 \%)$ of newborns passed meconium within 24 hours of life while only $2 \%$ babies passed meconium after 1 st day ( 24 hours-48 hours) suggesting that majority of newborns pass stool within 48 hours of life. Also, the study showed that majority $(99.8 \%$ ) of babies passed urine within first 12 hours while only $0.2 \%$ babies passed urine between 13-24 hours suggesting that most babies passed urine within first 12 hours.

\section{CONCLUSION}

It was observed in study that average time of passage of meconium in most of the babies were before 48 hours and passage of urine within 12 hours.

KEY WORDS Newborns, passage of meconium, passage of urine

1. Associate Professor, Department of Pediatrics, Universal College of Medical Sciences, Bhairahawa-32900, Nepal

2. Lecturer, Department of Pediatrics, Universal College of Medical Sciences, Bhairahawa-32900, Nepal

3. Junior Resident, Department of Pediatrics, Universal College of Medical Sciences, Bhairahawa-32900, Nepal

For Correspondence:

Dr. Badri Kumar Gupta

Associate professor

Department of Pediatrics

UCMS, Bhairahawa, Nepal

Email:drbadrikrgupta@gmail.com 


\section{INTRODUCTION}

Meconium is the earliest stool of a mammalian infant. Unlike later feces, meconium is composed of materials ingested during the time the infant spends in the uterus comprising of intestinal epithelial cells, lanugo, mucus, amniotic fluid, bile, and water. Meconium, unlike later feces, is viscous and sticky like tar and its color is usually dark olive green and almost odorless. When diluted in amniotic fluid, it may appear in various shades of green, brown or yellow. It should be completely passed by the end of the first few days after birth, with the stools progressing towards yellow (digested milk). ${ }^{1,2}$

The time of passage of newborn's first meconium or stool is an indicator of health and is used to screen for normal gastrointestinal tract function. Failure to pass meconium may be an early sign of intestinal obstruction or anatomical abnormality.

Most newborns urinate after birth, and this is an indication of normal renal function. Failure to pass meconium, stool, and urine within $1^{\text {st }} 24$ hours of birth is an important warning sign and indicates a requirement for further investigation. ${ }^{5}$

The study on the meconium and urinary patterns of Nepalese neonates during their stay in the hospital nursery room is sparse. Therefore, we carried out a prospective study to determine the meconium, stool, and urinary patterns of a newborn.

\section{MATERIAL AND METHODS}

A cross sectional hospital based observational study was conducted at a tertiary care hospital of western Nepal. Term clinically normal babies (weight $>2500$ grams and APGAR $>7 / 10$ ) delivered at UCMSTH within a period of 1 year from February 2014 to January 2015 were included in the study. Babies with congenital anomalies (imperforate anus, cleft lip and palate and spina bifida, colloidion baby), preterm babies, low birth weight babies and twin pregnancy were excluded from the study. Babies were checked 2 hourly by inspecting their diapers. For babies who had not passed stool and urine at discharge, the mobile phone number of the parents was used to contact the parents to report passage of first stool and urine. Statistical analysis was performed using statistical software (SPSS 15). Delayed passage of stool was considered if the newborn did not pass meconium by 48 hours and delayed passage of urine was considered if the newborn did not pass urine by first 24 hours.

\section{RESULTS}

The total delivered babies during the study period were 1050 . Among them 50 were excluded from the study. Total numbers of newborns included for the analysis were 1000. All babies were term and more than 2500 grams of weight as per inclusion criteria of study. The data summarized in table 1 shows that $97.8 \%$ newborns passed meconium within 24 hours of life and $2 \%$ passed meconium between $24-48$ hours.

Table 1. Showing frequency of passage of meconium at different hours of life

\begin{tabular}{|ll|}
\hline Passage of meconium in hours $(\mathbf{n}=\mathbf{1 0 0 0})$ & Number of babies $(\mathbf{N})(\mathbf{\%})$ \\
\hline Within 12 hours & $883(88.3)$ \\
12-24 hours & $95(9.5)$ \\
24-48 hours & $22(2.2)$ \\
\hline
\end{tabular}

Table 2 shows that $99.8 \%$ babies passed urine within first 12 hours of life whereas only $0.2 \%$ newborns passed urine between 12-24 hours of life.

Table 2 Showing frequency of passage of urine at different hours of life

\begin{tabular}{|ll|}
\hline Passage of urine $(\mathbf{n}=\mathbf{1 0 0 0})$ & Number of babies (\%) \\
\hline Within 12 hrs & $988(98.8)$ \\
$12-24$ hrs & $2(0.2)$ \\
\hline
\end{tabular}

\section{DISCUSSION}

Passage of first stool and urine within first 24 hours is a sign of fetal well-being. Passage of first stool is an important event in the first few days of life. There are various clinical conditions which can lead to the delay of passage of first stool (meconium). ${ }^{3,6}$

Majority of neonates pass their first stool within 24 hours of life. ${ }^{7}$ In the present study, $88.3 \%$ babies passed their first meconium within 12 hours, $97.8 \%$ babies within 24 hours and all babies (100\%) within 48 hours. Similarly, a study done on the first passage of first stool from Nigeria and Africa indicated that $96.2 \%$ of the babies passed their first stool within 24 hours and $99.8 \%$ in 48 hours. $^{8}$ Another study from Nigeria again supported the same findings. ${ }^{9}$ Many studies conducted in different countries also suggest findings similar to our study regarding passage of first stool. ${ }^{7,10-12}$

Therefore, passage of meconium after 24 hours can be considered delayed. As our study was a single centre study, multicentric studies can be considered in different parts of the country to have a proper definition of delayed passage of meconium in the context of Nepal.

Previous studies have reported that passage of the first stool is delayed in very low birth weight infants $(<1500 \mathrm{~g})$ because of 
the physiological immaturity of the motor mechanisms of the gut and the lack of the triggering effects of enteral food on gut hormones. ${ }^{13}$

Meconium passage is delayed and prolonged in preterm infants, and duration of meconium passage is associated with gestational age, birth weight, and morphine therapy. ${ }^{14}$

One of the limitations of the present study is that we did not include preterm babies. Hence, further studies can be considered comparing term and preterm babies with regard to the passage of first meconium in Nepalese babies.

Majority of newborns void within 24 hours of life. Urine formation is dependent on the total volume of body water, blood volume and renal perfusion. It may be enhanced by administration of parenteral fluids or by early feeding. ${ }^{10}$

In the present study, $98.8 \%$ babies voided within 12 hours and remaining $0.2 \%$ passed their first urine within 24 hours. Metaj et al in their study found that breast fed neonates passed urine earlier compared to formula fed babies.?

\section{CONCLUSION}

The average time of passage of meconium and first urine in most of the babies was before 48 hours and 12 hours respectively. Clinicians may reassure parents, if their newborn has not passed meconium 24 hours after birth, but they need to investigate such babies if they delay is beyond 48 hours. Similarly, newborns who do not void till 24 hours of life should be evaluated for the cause.

\section{CONFLICT OF INTERESTS: None}

\section{REFERENCES}

1. Kiely EM. Puri P. Newborn surgery. Oxford: ButterworthHeinemann; 1996. Meconium ileus; pp. 3247.

2. Aziz S, Anjum S, Rehman SA, Akram DS, Naqvi SA, Rizvi SA. Bilirubin pigments in the first meconium of newborn infants. JOURNAL-PAKISTAN MEDICAL ASSOCIATION. 2005 May; 55(5): 188.

3. Loening-Baucke V, Kimura K. Failure to pass meconium: diagnosing neonatal intestinal obstruction. Am Fam Physician. 1999 Nov 1;60(7):204350.

4. Khanna V, Poddar U, Yachha SK. Etiology and clinical spectrum of constipation in Indian children. Indian Pediatr. 2010 Dec; 47 (12) : 102530 .

5. Kayiran SM, EroĞlu E, Kayiran P, Sazak S, Gürakan B Meconium/stool and urinary patterns of healthy newborns. Marmara Medical Journal. 2012 Oct 1;25(3):143-7.
6. Fitzgerald JF. Constipation in children. Pediatrics in review. 1987 Apr;8(10):299-302.

7. Metaj M, Laroia N, Lawrence RA, Ryan RM. Comparison of breast-and formula-fed normal newborns in time to first stool and urine. Journal of perinatology. 2003 Dec;23(8):624.

8. Ogala WN, Amiebenomo CS. The time of passage of the first urine and stool by Nigerian neonates. Tropical and geographical medicine. 1986 Dec;38(4):415-7.

9. Ameh N, Ameh EA. Timing of passage of first meconium and stooling pattern in normal Nigerian newborns. Annals of tropical paediatrics. 2009 Jun 1;29(2):129-33.

10. Clark DA. Times of first void and first stool in 500 newborns. Pediatrics. 1977 Oct 1;60(4):457-9.

11. Sherry SN, Kramer I. The time of passage of the first stool and first urine by the newborn infant. The Journal of pediatrics. 1955 Feb 1;46(2):158-9.

12. Tunc VT, Camurdan AD, İlhan MN, Sahin F, Beyazova U. Factors associated with defecation patterns in 024-month-old children. European journal of pediatrics. 2008 Dec 1; 167 (12) : 1357-62.

13. Jhaveri MK, Kumar SP. Passage of the first stool in very low birth weight infants. Pediatrics. 1987 Jun 1;79(6):1005-7.

14. Bekkali N, Hamers SL, Schipperus MR, Reitsma JB, Valerio PG, Van Toledo L, Benninga MA. Duration of meconium passage in preterm and term infants. Archives of Disease in Childhood-Fetal and Neonatal Edition. 2008 Sep 1;93(5): F376-9. 